\title{
Construction of Evaluation Index system of Applied Undergraduate Course Based on Fuzzy Analytic Hierarchy Process
}

\author{
Wei $\mathrm{Li}^{1, \mathrm{a}}$ and Jingqiu Yang ${ }^{2, \mathrm{~b}}$ \\ ${ }^{1}$ Jilin Teachers'Institute of Engineering and Technology, Changchun, Jilin , China \\ 2 Jilin Teachers'Institute of Engineering and Technology, Changchun, Jilin , China \\ a414388426@qq.com; 'sf_7988@163.com
}

\begin{abstract}
Keywords: Evaluation index; Teaching reform; Evaluation system; Fuzzy analytic hierarchy process
\end{abstract}

\begin{abstract}
In view of the problems existing in the current applied undergraduate course evaluation neglect process evaluation and evaluation method, the course evaluation is divided into three stages: development, implementation and construction level, starting from the construction of curriculum evaluation index. A multivariate feedback evaluation index system of curriculum is constructed, and the quantitative analysis method and qualitative analysis method are combined with fuzzy analytic hierarchy process to make the evaluation method and result more reasonable.
\end{abstract}

\section{Introduction}

Curriculum construction is an important part of school teaching construction and the core of teaching reform. Curriculum teaching evaluation plays an important role in curriculum construction. At present, there are still two problems in most curriculum evaluation methods. On the one hand, it pays too much attention to summative evaluation and lacks of process evaluation, thus neglecting the monitoring and feedback of the course construction process. On the other hand, quantitative or qualitative evaluation is generally used in evaluation methods, but both methods have their own limitations, which affect the accuracy of evaluation results.

In order to solve the above problems, a multivariate feedback evaluation method is constructed. The AHP method is used to determine the evaluation index, and the fuzzy comprehensive evaluation method is used to realize the quantitative and qualitative comprehensive evaluation. Therefore, the course construction can be evaluated scientifically and reasonably.

\section{Evaluation of Multiple Feedback Applied Undergraduate Courses}

The multi-feedback applied undergraduate course evaluation system regards curriculum development and evaluation as a complete closed-loop system, which is based on the principle of automatic control. The evaluation expert group is composed of teachers and enterprise experts. The course experts are formed together, and the process evaluation of each work link of the curriculum development is carried out, and the timely feedback to the curriculum constructor, which realizes the real-time monitoring of the curriculum construction process by the curriculum evaluation. Ensure the course construction quality of the work process.

Based on the characteristics of applied undergraduate courses, the multi-feedback curriculum evaluation system is divided into three stages: curriculum development, implementation and construction. Three stages complement each other, and different stages carry out different contents of curriculum construction and evaluation.

According to the idea of multivariate feedback evaluation, when the evaluation feedback is introduced into every link of curriculum development, the next step can only be entered when the link is qualified, and if it is not qualified, the current link work should be rectified immediately. Thus, curriculum evaluation is a process of evaluation, improvement and improvement.

\section{Basic Principles of Analytic Hierarchy Process}

The Analytic hierarchy process, also known as the multilevel weight analysis method, was developed by Saaty, a leading operations researcher in the United States. Proposed in the early 1970s. This method is a multi-objective decision making method combining quantitative and qualitative analysis. The decision problem is decomposed into different hierarchies according to the overall objective, the sub-objectives of each layer, the evaluation criteria and the specific alternatives. It can effectively analyze the nonsequential relationships among the hierarchy of target criteria, and effectively synthesize the judgment and comparison of the decision makers. It can quantify the 
qualitative factors, test and reduce the subjective influence to a certain extent, and make the evaluation more objective and scientific.

In this paper, AHP is used to determine the evaluation index and its weight, and then the weight coefficient is obtained by analyzing and comparing the importance of each index, and the reasonableness of the judgment process can be ensured by the consistency test.

\section{Evaluation Process of Layered Courses based on Fuzzy Comprehensive Evaluation}

Establishment of evaluation index system. According to the principle of AHP, the system is hierarchical, and the primary evaluation index is determined as the three stages of curriculum evaluation, and the three evaluation indexes are established. $\mathrm{V}=\left\{\mathrm{V}_{1}, \mathrm{~V}_{2}, \mathrm{~V}_{3}\right\}=\left\{\right.$ curriculum development stage of $\mathrm{V}_{1}$ 、 curriculum implementation Stage of $\mathrm{V}_{2}$ 、 curriculum construction stage of $\mathrm{V}_{3}$ \}. Then, according to the main work in each stage of curriculum development, the secondary evaluation index is determined, and the multi-feedback curriculum evaluation index system is constructed.

In order to achieve the scientific and comprehensive curriculum evaluation effect, the first class index of curriculum evaluation is set to three stages, and 15 secondary indicators reflecting the specific connotation are shown in Table 1.

Table 1. Evaluation indicators of classroom teaching quality

\begin{tabular}{|c|c|c|c|}
\hline \multirow{5}{*}{$\begin{array}{l}\text { Course } \\
\text { implementation } \\
\text { stage }\end{array}$} & 1 & $\begin{array}{l}\text { Course teaching design: can design the teaching method and } \\
\text { teaching evaluation according to the course content and teaching } \\
\text { characteristics. }\end{array}$ & \multirow{5}{*}{0.3} \\
\hline & 2 & $\begin{array}{l}\text { Application of teaching means: reasonably use modern } \\
\text { information technology and other means to reform traditional } \\
\text { teaching methods, teaching means and teaching management, and } \\
\text { use the network for teaching and management. }\end{array}$ & \\
\hline & 3 & $\begin{array}{l}\text { Basic resources construction of courses: the quality of basic } \\
\text { resources of courses is high, which can reflect the teaching } \\
\text { philosophy, teaching thought and teaching design. }\end{array}$ & \\
\hline & 4 & $\begin{array}{l}\text { Resources development: strengthen the construction of network } \\
\text { courseware, teaching videos and other aspects, and realize the } \\
\text { sharing of high-quality teaching resources. }\end{array}$ & \\
\hline & 5 & $\begin{array}{l}\text { Course teaching effect: integrating theory with practice, paying } \\
\text { attention to knowledge dissemination, ability cultivation and } \\
\text { quality education. }\end{array}$ & \\
\hline \multirow{4}{*}{$\begin{array}{l}\text { Course } \\
\text { construction } \\
\text { level stage }\end{array}$} & 1 & $\begin{array}{l}\text { Course application effect: flexible application of advanced } \\
\text { teaching methods can effectively mobilize the enthusiasm of } \\
\text { students and explore the reform of assessment mode. }\end{array}$ & \multirow{4}{*}{0.3} \\
\hline & 2 & $\begin{array}{l}\text { Results of teaching and research reform: reform of curriculum } \\
\text { system, revision of teaching syllabus, compilation and publication } \\
\text { of teaching materials, and reform of teaching methods. }\end{array}$ & \\
\hline & 3 & $\begin{array}{l}\text { Course management: establish the management standard of course } \\
\text { teaching documents, implement the responsibility system of } \\
\text { course construction and the network management of course } \\
\text { resources. }\end{array}$ & \\
\hline & 4 & $\begin{array}{l}\text { Curriculum update: integrate advanced teaching experience and } \\
\text { educational reform results into curriculum construction in time, } \\
\text { and constantly improve the level of curriculum construction. }\end{array}$ & \\
\hline
\end{tabular}

Set up the field of rating, that is, set up the evaluation set: $=$ excellent, good, medium, average, poor $\}$. Set the weight vector of the evaluation factor: $\mathrm{a}=(0.4,0.3,0.3)$.

Construction of Judgement Matrix. Evaluation matrix is determined by fuzzy mapping from index set to evaluation set. Consider that a team of experts will be invited to evaluate the course evaluation. Therefore, according to each evaluation index, the nine-scale method is used to compare the indicators, such as Table 2, the judgment matrix is obtained. 
Table 2. The degree of importance of the criteria for the assignment of elements in the judgment matrix

\begin{tabular}{|c|l|}
\hline Scale & \multicolumn{1}{|c|}{ Meaning } \\
\hline 1 & Two factors are of equal importance. \\
\hline 3 & Denotes two factors, one of which is slightly more important than the other. \\
\hline 5 & Denotes two factors, one of which is significantly more important than the other. \\
\hline 7 & Denotes two factors, one of which is more important than the other. \\
\hline 9 & Denotes two factors, one of which is more important than the other. \\
\hline $2,4,6,8$ & Represents the median value of the above two adjacent judgments. \\
\hline Reciprocal & If the ratio of $a_{i}$ to $a_{j}$ is $a_{i j}$, then the ratio of y to x is $a_{j i}=1 / a_{i j}$. \\
\hline
\end{tabular}

Fuzzy comprehensive evaluation. Combining the index weights $A$ determined by the analytic hierarchy process , computationally fuzzy comprehensive evaluation, that is $B=A \cdot R$, Finally, the final evaluation level

was obtained by using the maximum membership principle. the $C I$ bigger, the greater the deviation from consistency,the smaller the deviation, the smaller the consistency. In addition, the $n$ bigger, the larger the subjective factors of judgment, the greater the deviation and the greater the consistency of deviation. When $n \leq 2, C I=0$, which means that the judgment matrix is completely consistent. Then calculate their consistency index values for each random sample matrix, averaging these $C I$ mean random consistency index $R l$.Saaty calculation $R l$ the value is constructed by random method, the consistency index is obtained by repeated calculation, and the value is obtained by averaging.

The consistency ratio $\quad C R=\frac{C I}{\text { is }}$ used to test the consistency of the judgment matrix. the $C R$ smaller, the matrix the better the consistency. ${ }^{R}$ General if $\boldsymbol{C R} \leq 0.1$, the judgment matrix meets the satisfied consistency criterion, otherwise, the judgment matrix needs to be modified until the test is passed.

\section{Concluding remarks}

In this paper, fuzzy mathematics is used to evaluate the course. Through the establishment of the fuzzy comprehensive evaluation model, the qualitative analysis and quantitative analysis are combined well, and the analytic hierarchy process is introduced to determine the weight of the course evaluation. Breaking through the way of expressing human subjective judgment in quantitative form, the research object is regarded as a system, which provides an effective method for determining the weight of evaluation index in the fuzzy evaluation of curriculum evaluation system. It provides theoretical basis and practical steps for the organization of applied undergraduate course evaluation in the future, and has extensive practical value.

\section{Acknowledgements}

Jilin provincial education department's 13th five-year social science project 2018.Project name: study on the mechanism and mode of university-enterprise cooperation in application-oriented universities.Contract no. : JJKH20180504SK

\section{Reference}

[1] Yang Xiaomin. Study on the methods and methods of Curriculum Evaluation in higher Vocational Education [J]. Vocational Education Research 2011 (11).

[2] Liu Huimin. The Application of Analytic hierarchy process in the Evaluation of Teachers'Teaching quality in higher Vocational Colleges [J]. Higher vocational educationJournal of Tianjin Vocational University,2008 (12)

[3] Jia Haiying, Dong Gang, Yang Lilian. Research and Development of Curriculum Evaluation Program in higher Vocational Education [J]. Research on higher Education in China, 2013 (8).

[4] Hu Xianfu. Application of Analytic hierarchy process in classroom Teaching quality Evaluation [J]. Journal of Hubei Adult Education College,2008(2):9-11.

[5] Yang Lubiao, Gao Yingyi. Principle and Application of Fuzzy Mathematics [M]. South China University of T echnology Press, 2005,6. 